\title{
Temporal and Spatial Scaling of the Genetic Structure of a Vector-Borne Plant Pathogen
}

\author{
Helvécio D. Coletta-Filho, Carolina S. Francisco, and Rodrigo P. P. Almeida
}

First and second authors: IAC-Centro APTA Citros Sylvio Moreira, Cordeirópolis, São Paulo, Brazil; second author: UNESP-Campus de Jaboticabal, São Paulo, Brazil; and third author: Department of Environmental Science, Policy, and Management, University of California, Berkeley.

Accepted for publication 12 September 2013.

\begin{abstract}
Coletta-Filho, H. D., Francisco, C. S., and Almeida, R. P. P. 2014. Temporal and spatial scaling of the genetic structure of a vector-borne plant pathogen. Phytopathology 104:120-125.

The ecology of plant pathogens of perennial crops is affected by the long-lived nature of their immobile hosts. In addition, changes to the genetic structure of pathogen populations may affect disease epidemiology and management practices; examples include local adaptation of more fit genotypes or introduction of novel genotypes from geographically distant areas via human movement of infected plant material or insect vectors. We studied the genetic structure of Xylella fastidiosa popu-

lations causing disease in sweet orange plants in Brazil at multiple scales using fast-evolving molecular markers (simple-sequence DNA repeats). Results show that populations of $X$. fastidiosa were regionally isolated, and that isolation was maintained for populations analyzed a decade apart from each other. However, despite such geographic isolation, local populations present in year 2000 were largely replaced by novel genotypes in 2009 but not as a result of migration. At a smaller spatial scale (individual trees), results suggest that isolates within plants originated from a shared common ancestor. In summary, new insights on the ecology of this economically important plant pathogen were obtained by sampling populations at different spatial scales and two different time points.
\end{abstract}

Genetic structure of pathogen populations can be studied at multiple spatial and temporal scales. Analyses of pathogen populations within one or multiple individual hosts within a population (e.g., patients in a hospital) have led to insights on transmission dynamics and pathogen adaptation $(23,25)$. At larger geographical scales, comparisons among local and regional pathogen populations allow for inferences on the origin of epidemics or pathogen movement within the landscape (37). Within-host pathogen dynamics may also be studied by genotyping isolates from infected individuals over time (47). Therefore, population genetics of pathogens are widely used to address questions of ecological relevance.

Pathogens of perennial agricultural crops are unique in that hosts are immobile and long lived. These host populations are subject to a range of pathogens, many of which are dispersed by air or water (i.e., rain), while others require biological vectors for spread between individuals. Because many diseases affecting perennial crops have long incubation periods, it is often difficult to infer dispersal patterns or understand the history of epidemics based on host symptoms alone. Population genetics tools and approaches are applicable in these scenarios to infer pathogen dispersal patterns (22). Here, we analyzed genetic structure of a plant pathogen at various scales, from plants to regions, at two time points one decade apart.

Citrus variegated chlorosis (CVC) is a disease caused by the bacterium Xylella fastidiosa subsp. pauca (40). This bacterium colonizes xylem vessels of sweet orange trees (Citrus sinensis),

Corresponding author: R. P. P. Almeida;

E-mail address: rodrigoalmeida@berkeley.edu

* The $\boldsymbol{e}$-Xtra logo stands for "electronic extra" and indicates that the online version contains two supplemental figures and four supplemental tables. Figure 2 appears in color online.

http://dx.doi.org/10.1094/PHYTO-06-13-0154-R

(C) 2014 The American Phytopathological Society resulting in blockage of sap flow and a variety of symptoms, including stunting, leaf chlorosis, and small fruit (17). Plant-toplant transmission is mediated exclusively by xylem-sap-feeding leafhoppers of various species (1). Although $X$. fastidiosa colonizes a range of alternative host plant species, epidemiological work indicated that spread within orchards is dominated by citrus-tocitrus vector transmission (27). Since its origin in 1987 in northern São Paulo state, Brazil, CVC quickly spread throughout the state and the country. Genetic structuring within the state was observed and found to be driven by the geographical location of populations (13) rather than $C$. sinensis variety (12). Importantly, disease symptoms and incidence vary in the state, suggesting that different pathogen populations may be more adapted to specific local conditions. If that were the case, one would expect locally adapted populations to be recalcitrant to introduction of less-fit genotypes from other regions. Because replacement of bacterial plant pathogen populations has been observed in crops (38), it is important to determine whether pathogen population replacement has occurred over time for diseases of perennial crops. The replacement of pathogen populations could, in the long term, lead to dissimilar disease control strategies, because distinct populations would differentially affect host crops (41).

In addition to the potential effect of population structuring at the regional level, another important question for vector-borne pathogens of perennial crops is the number of infection events each plant experiences. If an individual plant harbors only one pathogen genotype or only descendants of the original genotype, then those individuals could be assumed to have been systemically infected only once (unless multiple infections with the same genotype have occurred). On the other hand, multiple infections may have occurred if multiple genotypes are detected within that plant. Competitive exclusion theory suggests that only one pathogen genotype per species should occur in infected hosts but that is often not the case; multiple pathogen infections are common in perennial crops, including multiple pathogen species or strains of the same species (42). In addition to ecological questions associ- 
ated with population fitness, determining the number of infection events that lead to systemic host colonization is of epidemiological importance, because it may help determine thresholds of vector populations within orchards below which disease incidence would be reduced (36).

Objectives of this study were to determine distribution of genetic diversity in $X$. fastidiosa populations across a hierarchy of macro (regional) and micro (branches within each tree) spatial scales, as well as the effect of time on genetic structure of populations one decade apart from each other. Fast-evolving simplesequence DNA repeat (SSR) markers were used, because they have been previously shown to provide adequate resolution for $X$. fastidiosa populations (10). These analyses provide information on the genetic diversity of field populations, as well as the consequences of vector transmission of $X$. fastidiosa on the structure of these populations. On the smallest scale, the study aimed to determine the number of infection events that have led to systemic plant colonization, which can be interpreted as the pathogen genetic carrying capacity of a host plant. Altogether, the results provide insights on the ecology of $X$. fastidiosa pathogens that may also be conceptually extrapolated to other vector-borne plant pathogens.

\section{MATERIALS AND METHODS}

Field sampling, bacterial isolation, and DNA extraction. We analyzed SSR loci variation in 320 X. fastidiosa subsp. pauca isolates infecting sweet orange (C. sinensis) trees in São Paulo State, Brazil. Isolates were obtained a decade apart from each other, in 2000 and 2009 (160 isolates per period), and collected at four different geographic regions of the State: Northwest $(\mathrm{Nw})$, Central (Ce), Center-West (Cw), and East (Ea) (Supplemental Figure 1). Although populations were collected from the same regions in 2000 and 2009, individual sites were not the same; the sampling strategy was also slightly different. Populations in the same region for both sampling periods were no more than 70 kilometers from each other; sampling of the same orchards was not possible because of orchard removal due to CVC. In 2009, isolates were obtained by culturing from a single 2- to 3-cm-long branch; if possible, five isolates were obtained per branch after triple cloning. Four branches were sampled per tree and four trees per region (same orchard). The final number of samples per branch varied due to uneven $X$. fastidiosa isolation success from field tissue. DNA from 160 isolates obtained in 2000 from the same regions used in a previous study was also amplified (13); isolates were recovered from storage at $-80^{\circ} \mathrm{C}$. For these, we analyzed two to four isolates per tree (obtained from independent samples) for a total of 12 trees per region, with the exception of region Nw, for which 10 trees were sampled. Protocols used for bacterial isolation, clonal purification, and other protocols in 2009 were the same as for the 2000 population (13).

Amplification of SSR loci and fragment analysis. Fourteen SSR loci were used to type isolates, based on repeats previously identified (Supplemental Table 1) (10,31). We used polymerase chain reactions (PCRs) with three or four multiplexed primer sets each. Multiplex amplifications were performed in a final volume of $12.5 \mu \mathrm{l}$ containing 25 to $50 \mathrm{ng}$ of DNA, $6.25 \mu \mathrm{l}$ of Taq PCR Master Mix kit (Qiagen, Valencia, CA), and variable primer pair concentrations (with a fluorescent labeled forward primer) (Supplemental Table 2). The following program was used for PCR amplification of the loci: a denaturation step at $95^{\circ} \mathrm{C}$ for $6 \mathrm{~min}$, followed by 35 cycles at $95^{\circ} \mathrm{C}$ for $30 \mathrm{~s}, 56^{\circ} \mathrm{C}$ (primer set A) or $57^{\circ} \mathrm{C}$ (primer sets $\mathrm{B}, \mathrm{C}$, and $\mathrm{D}$ ) for $30 \mathrm{~s}$, and a 2 -min extension at $65^{\circ} \mathrm{C}$ (primers set $\mathrm{A}$ and $\mathrm{B}$ ) or $68^{\circ} \mathrm{C}$ (primers set $\mathrm{C}$ and $\mathrm{D}$ ). Prior to capillary electrophoresis, $0.5 \mu \mathrm{l}$ of the amplified product was added to $12 \mu \mathrm{l}$ of Hi-Di Formamide with $0.3 \mu \mathrm{l}$ of GeneScan 500LIZ Size Standard (both from Life Technology, Foster City, CA). After DNA denaturation for $5 \mathrm{~min}$ at $95^{\circ} \mathrm{C}$, followed by cooling in ice for $2 \mathrm{~min}$, samples were submitted to capillary electrophoresis in an ABI 3730xl DNA sequencer (Life Technology) with the LIZ500-3730 standard setting on GeneScan module with filter set G5. Data capture from sequencer and analysis of allele size followed previously described methodology (10).

SSR information content. Allele frequency distributions and other data, such as range of repeat size and number of alleles per locus, for the 14 SSR loci are available in the supplemental material (Supplementa1 Table 4; Supplemental Figure 2). For visualization of SSR dynamics within the population, alleles were binned into fragment size categories using the program FLEXIBIN (2). Considering the observed repeat unit increments where the mutations involved single-repeat changes (the insertion or deletion of one repeat motif) for most of the SSR loci, as also previously found for $X$. fastidiosa subsp. fastidiosa (10), a stepwise mutation model was assumed for all analyses.

Clonal and genetic diversity. The multilocus microsatellite genotype (MLMG) for each isolate was determined using the GenoDive software (34), where samples with the same MLMG were treated as clones of a single haplotype. We determined three indices of clonal diversity: (i) the number of observed genotypes per population $\left(\mathrm{N}_{0}\right)$; (ii) the clonal fraction [1 - (number of different genotypes within the population)/(total number of isolates within the population)] (48); and (iii) the Simpson's diversity index $(\mathrm{Si})$, which was estimated as $S i=1-\Sigma P_{r}^{2}(r=1$ to $\mathrm{s})$, where $P_{r}$ is the relative abundance of the $r$ th genotype in the population (1 represents infinite diversity and 0 no diversity) (24). For all further analyses, only one representative of each haplotype was selected per population to construct clone-corrected data sets for both 2000 and 2009 populations.

The mean of genetic diversity $\left(\mathrm{H}_{\mathrm{Nei}}\right)$, corrected by the number of individuals $(n)$ in a population $\left(\mathrm{H}_{\mathrm{Nei}}=\left[\left(1-\Sigma p_{i}^{2}\right) \times(n / n-1)\right]\right)$, where $p_{i}$ is the frequency of allele $i$ at the locus p (35), was estimated using the software FSTAT, version 2.9.3.2 (21), with statistics for the significance between pairs of comparisons obtained by 1,000 randomizations.

Differentiation among populations. We used analysis of molecular variance (AMOVA) with ARLEQUIN 3.11 software (19) to quantify genetic variation among samples for spatial and temporal structure of $X$. fastidiosa populations. Spatial structure was analyzed for both 2000 and 2009 populations. For 2009, we also estimated small-scale structure by analyzing genetic variation occurring from branches to trees within each geographic region, and at large-scales we tested the effect of geographical distance on genetic structure of these populations. For the 2000 population, structure was analyzed by considering genetic variation within trees, among trees within orchards, and among orchards (i.e., regions). The effect of time on genetic variation was tested among populations sampled in 2000 and 2009. For all AMOVAs, the sum of squared size differences $\left(\Phi_{\mathrm{STAT}}\right)$ between two haplotypes was used as a distance measure (43) and significance was assessed using 10,100 permutation tests.

The null hypotheses of no genetic differentiation among sampled populations were tested by $D_{\text {est }}(26)$ using the DEMETICS package in the software package R (20). Populations were significantly differentiated when $D_{\text {est }}$ values were $>95 \%$ of the values obtained by 1,000 bootstrapping of MLMG over populations. $D_{\text {est }}$ is based on $\mathrm{G}_{\mathrm{ST}}$ statistics but more adapted to highly polymorphic markers such as SSR (20). The Mantel test of isolation by distance for 2000 and 2009 populations was carried out with GenoDive, assuming linear relationship between pairwise $D_{\text {est }}$ and the geographic distance (kilometers) between all pairwise populations (39).

Clustering analysis by individual. From the $X$. fastidiosa populations sampled in 2009, we also determined the number of genetically homogeneous clusters or populations in each of the predefined levels of structure (branch, tree, and orchard). The Bayesian method of assignment run by the BAPS software was 
used (16). The method assumes that the target population is genetically structured but shape and extension of such structure is unknown. We ran BAPS using the "cluster of individuals" function and the mixture model, as previously recommended, as the best option for estimating the number of populations (46), setting the number of clusters at 2 to 30 for each predefined level of tested structure. From the most appropriate $K$ value (i.e., number of clusters), we reran BAPS using the "Fixed-K module" using 1,000 runs to identify clusters members.

\section{RESULTS}

SSR are subspecies-specific in $X$. fastidiosa. This work initially used 20 SSR primer sets that were previously employed to study the ecology of $X$. fastidiosa subsp. fastidiosa infecting grapevines (10). Because several monomorphic bands were observed, all loci were checked with an in silico analysis of the $X$. fastidiosa subsp. pauca isolate 9a5c genome. In all, 7 of the 20 primer sets amplified nonrepeat regions and one set (ASSR-19) did not result in an amplicon. The CSSR-10 primer pair resulted in multiple peaks for many samples (data not shown). Therefore, those loci $(n=9)$ were not used; 3 other SSR loci (SSR28, SSR30, and SSR40) (13) were added, resulting in 14 SSR loci used in this study. These loci were polymorphic for all populations studied and the number of alleles for each locus was 3 to 19 alleles, with a total of 146 alleles for the 14 loci.

Gene and genotype diversity remained high from 2000 to 2009. In all, 86 and 58 MLMGs were found in samples from 2000 and 2009, respectively (Table 1). The clonal fraction among isolates was higher in 2009 than 2000 for three of the four regions sampled; a similar trend was observed for genotype diversity (Simpson's index). The clonal fraction was 0.35 to 0.80 , suggesting that populations of $X$. fastidiosa subsp. pauca colonizing citrus are more clonal than those of subsp. fastidiosa in grapevines (10), although different sampling strategies were used. Different regions had distinct indices of genetic diversity and allelic richness. Notably, the Nw population had a smaller clonal fraction and higher genetic diversity and allelic richness than most other populations in both 2000 and 2009. Interestingly, both disease severity and incidence appear to be higher in the Nw region (11).

Genetic structure of populations among regions was maintained over a decade. AMOVA showed significant contribution of time and space to genetic diversity of $X$. fastidiosa populations. At the small scale, variability of haplotypes within branches in the 2009 populations represented $13.60 \%\left(\Phi_{\text {STAT }}=0.86\right)$ of total variance (Table 2). A significant contribution to genetic diversity was observed "within the trees" for the $\mathrm{Nw}, \mathrm{Cw}$, and $\mathrm{Ea}$ populations. But an extremely low and nonsignificant value of population differentiation $\left(\%\right.$ Variation $\left.=-0.57, \Phi_{\mathrm{STAT}}=0.02\right)$ was observed in the Ce population (Table 2), whereas variation of genetic diversity "among the trees" was substantially higher $(79.24 \%$ for overall population). At a larger geographic scale, variation within populations represented $55.03 \%$ of total genetic variation while variation among populations was $44.97 \%$ of total.

Populations collected in 2000 also had a strong and statistically significant genetic differentiation among regions $\left(\Phi_{\text {STAT }}=0.85\right.$, $P<0.001)$, which explained $43 \%$ of total genetic variance. Statistically significant variation among plants $\left(\Phi_{\text {STAT }}=0.75, P<\right.$ $0.001)$ and within each plant $\left(\Phi_{\text {STAT }}=0.43, P<0.001\right)$ accounted for $\approx 43$ and $14 \%$ of total genetic variation observed, respectively. Differences were also significant in an overall comparison between contemporary (2009) versus early (2000) samples (4.92\%, $\left.\Phi_{\text {STAT }}=0.05\right)$, and the same was observed for each geographic region with high values of variation (Table 2). Variation within populations for both 2000 or 2009 was the main source of variability.

Reinforcing the AMOVA results, significant $D_{\text {est }}$ values were consistently observed for population pairs among regions (Table 3). Pairwise comparisons of sympatric populations (i.e., those from the same region but sampled one decade apart), in general, had the smallest values of genetic differentiation $\left(D_{\text {est }}=0.13\right.$ to $0.24)$ but were still statistically different $(P<0.05)$. Thus, time

TABLE 1. Genotypic and genetic diversity of Xylella fastidiosa isolates from populations in São Paulo (Brazil)

\begin{tabular}{|c|c|c|c|c|c|c|}
\hline Region & Population $^{\mathrm{w}}$ & MLMG $^{\mathrm{x}}$ & Clonal fraction & Simpson index ${ }^{y}$ & $\mathrm{H}_{\mathrm{Nei}}{ }^{\mathrm{z}}$ & Allelic richeness $^{2}$ \\
\hline \multirow[t]{2}{*}{ Northwest } & 2009 & 26 & 0.35 & $0.96 \mathrm{~b}$ & $0.66 \mathrm{~b}$ & $3.82 \mathrm{bc}$ \\
\hline & 2000 & 21 & 0.48 & $0.95 \mathrm{~b}$ & $0.63 b$ & $4.05 \mathrm{~b}$ \\
\hline Central & 2009 & 11 & 0.73 & $0.80 \mathrm{~d}$ & $0.42 \mathrm{ab}$ & $2.56 \mathrm{a}$ \\
\hline \multirow[t]{2}{*}{ Center-west } & 2009 & 8 & 0.80 & $0.67 \mathrm{a}$ & $0.41 \mathrm{ab}$ & $2.21 \mathrm{a}$ \\
\hline & 2000 & 23 & 0.43 & $0.95 \mathrm{~b}$ & $0.46 \mathrm{ab}$ & $3.08 \mathrm{ab}$ \\
\hline \multirow[t]{2}{*}{ East } & 2009 & 13 & 0.68 & $0.89 \mathrm{c}$ & $0.36 \mathrm{ab}$ & $2.56 \mathrm{ac}$ \\
\hline & 2000 & 22 & 0.45 & $0.91 \mathrm{c}$ & $0.29 \mathrm{a}$ & $2.31 \mathrm{a}$ \\
\hline
\end{tabular}

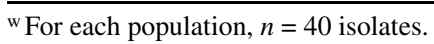

${ }^{x}$ Number of multilocus microsatellite genotypes (MLMGs).

y Simpson diversity index by Genodive (v. 2.0). Means followed by the same letter were significantly different $(P \leq 0.05)$ based on 1,000 pairwise permutations.

${ }^{\mathrm{z}}$ Nei's unbiased gene diversity $\left(\mathrm{H}_{\mathrm{Nei}}\right)$ and allelic richness were estimated by FSTAT (v. 2.9.3) with the statistic significance based on 1,000 permutations.

TABLE 2. Analysis of genetic variation among populations structured in space or time

\begin{tabular}{|c|c|c|c|c|c|}
\hline \multirow[b]{2}{*}{ Population $^{\mathrm{w}}$} & \multicolumn{5}{|c|}{$\%$ Variation; $\Phi_{\mathrm{STAT}}{ }^{\mathrm{x}}$} \\
\hline & Northwest & Central & Center-west & East & Overally \\
\hline \multicolumn{6}{|l|}{ Space (2009) } \\
\hline Among trees within orchard & $65.67 ; 0.65 * * *$ & $80.64 ; 0.80 * * *$ & $81.70 ; 0.81 * *$ & $50.67 ; 0.50 * *$ & $79.24 ; 0.79 * * *$ \\
\hline Among branches within trees & $13.21 ; 0.38 * * *$ & $-0.57 ; 0.02 \mathrm{~ns}$ & $11.41 ; 0.62 * * *$ & $21.02 ; 0.42 * * *$ & $7.16 ; 0.84 * * *$ \\
\hline Within branches ${ }^{\mathrm{z}}$ & $21.12 ; 0.79 * * *$ & $19.93 ; 0.80 * * *$ & $6.89 ; 0.93 * * *$ & $28.31 ; 0.71 * * *$ & $13.60 ; 0.54 * * *$ \\
\hline \multicolumn{6}{|l|}{ Time } \\
\hline Between 2000 and 2009 & $12.79 ; 0.12 * * *$ & $32.27 ; 0.32 * * *$ & $25.40 ; 0.25 * * *$ & $20.43 ; 0.20 * * *$ & $4.92 ; 0.05 * * *$ \\
\hline Within each population & 87.21 & 67.73 & 74.60 & 79.27 & 95.08 \\
\hline
\end{tabular}

${ }^{w}$ Population structure and source of variation.

${ }^{x}$ Geographic regions in São Paulo State/Brazil; ** and *** indicate $P<0.01$ and 0.001 , respectively; ns $=$ not significant.

y All regions were analyzed together without the origin inference.

${ }^{\mathrm{z}}$ Five isolates within each branch. 
was also an important factor affecting population structure. These data support the hypothesis that genetic structure of $X$. fastidiosa populations are shaped by geographic regions However, no evidence of isolation based on geographical distance was found (Fig. 1). It is possible that pathogen dispersal via contaminated plant material, common prior to 2000 , resulted in the establishment of local populations that have been maintained over time.

Genotypic structure within trees suggests primarily a single infection event in each host. A Bayesian clustering approach was used to infer the number of genetic clusters $(K)$ in 2009 populations. We tested clustering for the following populations: branches $(n=32)$, trees $(n=16)$, and regions $(n=4)$. The best number of clusters identified was $K=16$ (marginal likelihood of -1216.72 [branch and tree levels] and -1179.52 [regional level]). Interestingly, individuals clustered within each of the 16 clusters corresponded, with few exceptions (T3/T4-Ea, T1/T3-Cw, T2-Ce, and T1-Ea), to their own respective tree-source $\left(\mathrm{T}_{n}\right)$ (Fig. 2). In other words, isolates were assigned to 16 different genetic clusters, which primarily represented the 16 sampled tress. Those results were confirmed by higher and significant values for population differentiation $\left(D_{\text {est }}\right)$ among tress within each geographic region (Supplemental Table 3), with exceptions for trees 1 and 3 from $\mathrm{Cw}$ and trees 3 and 4 from Ea regions, whose results completely agreed with the Bayesian analysis. Isolates from T2$\mathrm{Ce}$ and T1-Ea were split into two independent clusters (Fig. 2); these could represent independent infections of the same plant.

\section{DISCUSSION}

This study used two large sets of $X$. fastidiosa isolates obtained from symptomatic citrus plants in Brazil one decade apart from each other to address two main questions. First, did $X$. fastidiosa populations at different geographic regions of São Paulo State remain static over time? Results indicate that local populations persisted and were not replaced by invaders, yet local populations were genetically distinct. Second, how many X. fastidiosa infections may an individual citrus tree, as a perennial plant, harbor in different parts of its canopy? Results showed that although each tree harbored multiple pathogen haplotypes, individual trees in an orchard harbored distinct populations. These data indicate that, in most cases, isolates from one tree shared a common ancestor, supporting the idea that only one infection occurred per plant. Recent experimental work has demonstrated that co-inoculation of $X$. fastidiosa isolates within the same subspecies into plants does not lead to co-infections (4). However, because populations were geographically structured, an alternative interpretation of these data is that multiple infection events with genotypes from the same population occurred, and those may not have been detected. Larger sample sizes with more tress within orchards linked to epidemiological surveys estimating local disease progression parameters may be necessary to conclusively answer this question.

Of 320 typed isolates in this study, $45 \%$ had different haplotypes. This proportion is lower than that observed in a previous study of $X$. fastidiosa infecting grapevines in California (10). However, in both studies, moderate to high indices of genotypic diversity were observed. That was made evident by the fact that trees in the same orchard harbored genetically distinct $X$. fastidiosa populations but even populations from the same branch had clones that were not identical. Because the data suggest that isolates in one plant may share a common ancestor, the degree of diversity found in these populations is intriguing. SSR length variation is generated primarily due to slippage of the polymerase during replication, which results in indels at SSR loci $(44,45)$. As a consequence, the rate with which these errors occur varies in a locus-specific manner and is several orders of magnitude higher than point mutations in nonrepeat DNA regions (18). Bacterial repeats in protein coding or upstream of regulatory regions are responsible for phenotypic switches as well as cell adaptations to specific environmental challenges $(3,32)$. Here, most SSRs were located in housekeeping genes, noncoding regions, and hypothetical proteins $(14,31)$. An understanding of the functional role of SSR variation in $X$. fastidiosa may yield interesting insights.

A previous study demonstrated that $X$. fastidiosa populations infecting citrus in São Paulo state were geographically structured (13). This level of structuring is different from that observed in $X$. fastidiosa populations causing disease in grapevines in California (10). Because citrus is rather contiguous within the geographical area included in our field sites, geographical isolation with limited dispersal is one possible explanation for observed patterns. Management practices are similar throughout the state, although insect vector pressure varies across sampled citrus regions, as do mean temperature and rainfall distribution (13). Spatial clustering observed was interesting because populations established in 2000 were replaced by new and distinct populations in 2009. However, 2009 populations were more closely related to

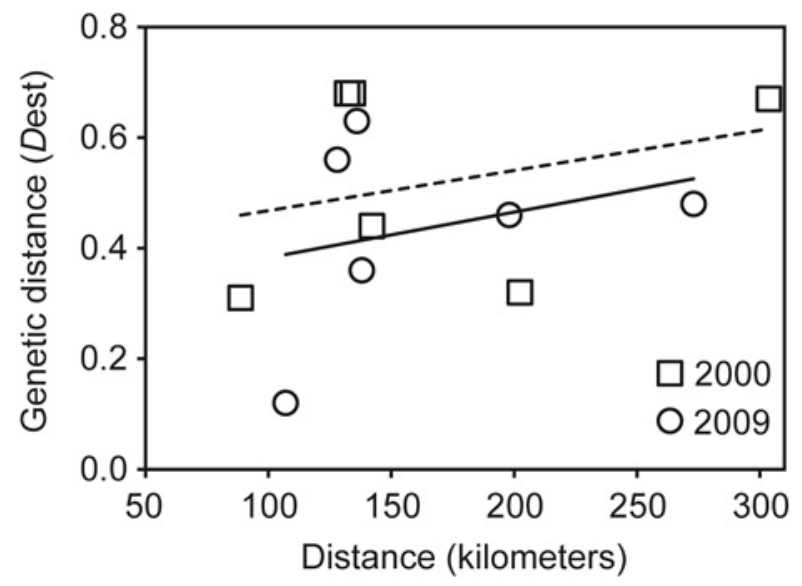

Fig. 1. Nonsignificant regressions between genetic and geographical distance among pairs of Xylella fastidiosa populations from São Paulo, Brazil, sampled in 2000 (open squares, dashed line; $P=0.446$ ) and 2009 (open circles, solid line; $P=0.393)$.

TABLE 3. Measures of pairwise population differentiation (based on $D_{\text {est }}$ statistics calculated with DEMETICS) ${ }^{\mathrm{z}}$

\begin{tabular}{|c|c|c|c|c|c|c|c|c|}
\hline$\overline{D_{\text {est }}}$ & Nw-09 & Nw-00 & $\mathrm{Ce}-09$ & $\mathrm{Ce}-00$ & Cw-09 & Cw-00 & Ea-09 & Ea-00 \\
\hline Nw-09 & $\ldots$ & $\ldots$ & $\ldots$ & $\ldots$ & $\ldots$ & $\ldots$ & $\ldots$ & $\ldots$ \\
\hline Nw-00 & 0.20 & $\ldots$ & $\ldots$ & $\ldots$ & $\ldots$ & $\ldots$ & $\ldots$ & $\ldots$ \\
\hline $\mathrm{Ce}-09$ & 0.63 & 0.62 & $\ldots$ & $\ldots$ & $\ldots$ & $\ldots$ & $\ldots$ & $\ldots$ \\
\hline $\mathrm{Ce}-00$ & 0.66 & 0.68 & 0.24 & $\ldots$ & $\ldots$ & $\ldots$ & $\ldots$ & $\ldots$ \\
\hline Cw-09 & 0.56 & 0.58 & 0.12 & 0.26 & $\ldots$ & $\ldots$ & $\ldots$ & $\ldots$ \\
\hline $\mathrm{Cw}-00$ & 0.56 & 0.68 & 0.17 & 0.31 & 0.13 & $\ldots$ & $\ldots$ & $\ldots$ \\
\hline Ea-09 & 0.48 & 0.66 & 0.36 & 0.48 & 0.46 & 0.37 & $\begin{array}{l}\cdots \\
\cdots\end{array}$ & $\ldots$ \\
\hline $\mathrm{Ea}-00$ & 0.55 & 0.67 & 0.45 & 0.44 & 0.49 & 0.32 & 0.14 & $\cdots$ \\
\hline
\end{tabular}

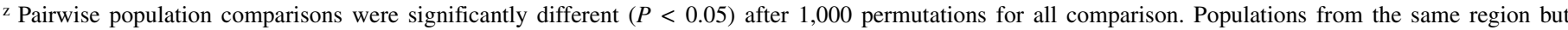
sampled over time $(2000=00$ and $2009=09)$ are in bold. Samples were collected from regions of São Paulo State: Nw = Northwest, Ce $=$ Central, Cw = CenterWest, and $\mathrm{Ea}=$ East. 


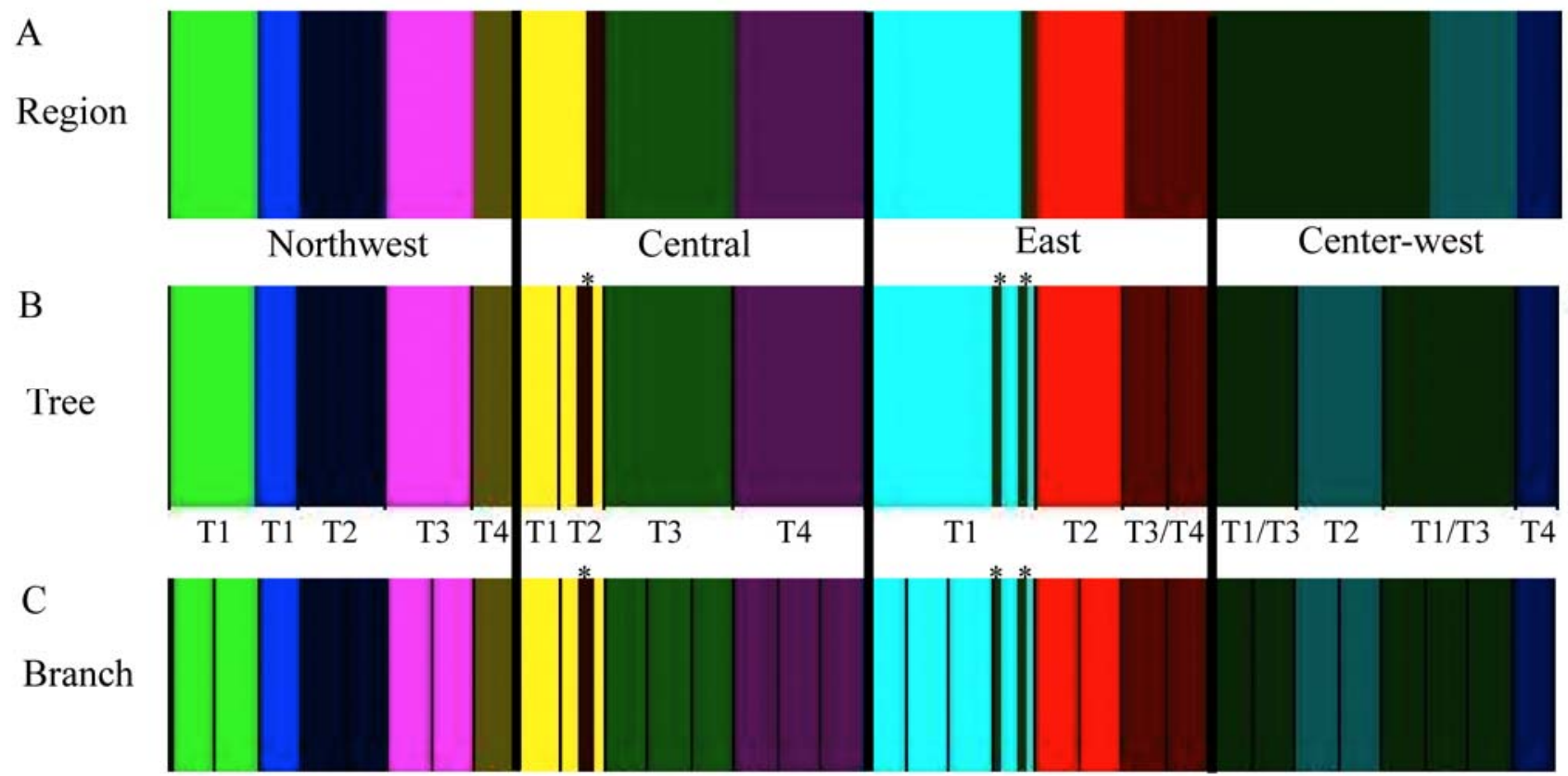

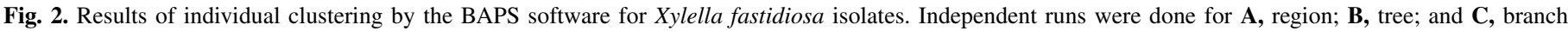

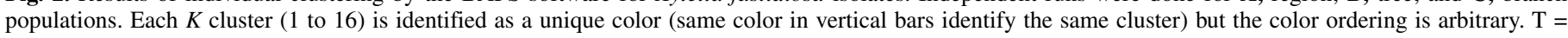

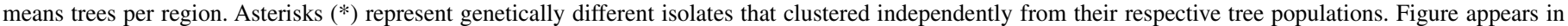
color online.

local predecessors in 2000 than to contemporary populations from other regions. It is possible that locally well-adapted genotypes outcompete invaders, effectively maintaining genetic cohesion and spatial structure of CVC-causing X. fastidiosa populations. The fact that citrus-to-citrus local vector transmission is the dominant mode of CVC spread in orchards (27) may also be an important driver of population structure. Due to the decade-long nature of this study, it was impossible to survey the same plants or orchards at both sampling periods; therefore, geographically close yet distinct $X$. fastidiosa populations were compared. This raises the possibility that differences between 2000 and 2009 populations were due to differences already present between geographic locations rather than those accumulated between sampling periods. Additionally, the sampling structure between 2000 and 2009 was slightly different. However, in both cases, statistical differences for genotypic and genetic parameters were similar and did not appear to be affected by sampling structure.

Because populations did not disperse over large geographical areas and individual trees hosted isolates that appeared to share a common ancestor, competition among genotypes is likely a strong factor affecting $X$. fastidiosa ecology. Experimental work under controlled conditions, aimed at testing whether competition occurs among similar yet distinct $X$. fastidiosa isolates within the same subspecies, has demonstrated that more fit isolates drive competitors to extinction when co-inoculated into plants (4). It should be mentioned that different subspecies of $X$. fastidiosa have been isolated from the same host (9) although, in that case, the large genetic distance may have decreased the impact of ecological competition or interference. Competitive exclusion and strong selective pressures such as temperature, vector species diversity, and ecology could lead to local adaptation of populations. It has been shown that, in a homogeneous environment, colicin-producing Escherichia coli genotypes prevent invasion by colicin-sensitive genotypes, and vice-versa (7). Toxin-antitoxin addiction systems have been described in $X$. fastidiosa $(29,30)$, and their role in the ecology of this bacterium should be considered (15).

The replacement of bacterial plant pathogen populations by more virulent genotypes is often brought up in the context of breakdown of resistance $(8,28,33)$. However, most of that work has not analyzed populations at multiple spatial scales. Furthermore, temporal aspects of resistance breaking are generally addressed by a change in effector profiles (i.e., one or few loci) $(5,6)$. The results presented here suggest that populations did not disperse over long distances naturally, and that genetic sweeps did not occur at any citrus-growing region of São Paulo state. This study also demonstrates that populations of $X$. fastidiosa causing CVC in Brazil are structured at multiple spatial scales, from individual plants to regions. These data, allied with the lack of regional movement of populations in one decade, provide support to the previously proposed hypothesis that environmental factors affecting CVC ecology in the various regions of the state result in the observed different levels of disease incidence (11).

\section{ACKNOWLEDGMENTS}

This work was funded by the California Department of Food and Agriculture. H. D. Coletta-Filho acknowledges CAPES/Brazil for a postdoctoral fellowship (project number 3663-08-6), which made this collaborative project possible, and for FAPESP (project number 2011/13803-9). We thank our lab colleagues for constructive suggestions and discussions and three anonymous reviewers for thoughtful comments that improved this manuscript.

\section{LITERATURE CITED}

1. Almeida, R. P. P., Blua, M. J., Lopes, J. R. S., and Purcell, A. H. 2005 Vector transmission of Xylella fastidiosa: applying fundamental knowledge to generate disease management strategies. Ann. Entomol. Soc. Am. 98:775-786

2. Amos, W., Hoffman, J. I., Frodsham, A., Zhang, L., Best, S., and Hill, A. V. S. 2007. Automated binning of microsatellite alleles: Problems and solutions. Mol. Ecol. Notes 7:10-14.

3. Aras, R. R., Kang, J., Tschumi, A. I., Harasaki, Y., and Blaseer, M. J. 2003. Extensive repetitive DNA facilitates prokaryotic genome plasticity. Proc. Natl. Acad. Sci. USA 23:13579-13584.

4. Baccari, C., and Lindow, S. E. 2011. Assessment of the process of movement of Xylella fastidiosa within susceptible and resistant grape cultivars. Phytopathology 101:77-84.

5. Barrett, L. G., Thrall, P. H., Burdon, J. J., and Linde, C. C. 2008. Life history determines genetic structure and evolutionary potential of host- 
parasite interactions. Trends Ecol. Evol. 23:678-685.

6. Barrett, L. G., Thrall, P. H., Dodds, P. N., van der Merwe, M., Linde, C. C., Lawrence, G. J., and Burdon, J. J. 2009. Diversity and evolution of effector loci in natural populations of the plant pathogen Melampsora lini. Mol. Biol. Evol. 26:2499-2513.

7. Bohannan, B. J. M., Kerr, B., Jessup, C. M., Hughes, J. B., and Sandvik, G. 2002. Trade-offs and coexistence in microbial microcosms. Antonie Leeuwenhoek 81:107-115.

8. Browning, J. A., and Frey, K. J. 1969. Multiline cultivars as means of disease control. Annu. Rev. Phytopathol. 7:355-382.

9. Chen, J., Groves, R., Civerolo, E. L., Viveros, A., Freeman, A., and Zheng, Y. 2005. Two Xylella fastidiosa genotypes associated with almond leaf scorch disease on the same location in California. Phytopathology 95:708-714.

10. Coletta-Filho, H. D., Bittleston, L. S., and Almeida, R. P. P. 2011. Spatial genetic structure of a vector-borne generalist pathogen. Appl. Environ. Microbiol. 77:2596-2601.

11. Coletta-Filho, H. D., Gonçalves, F. P., Amorim L., de Souza, A. A., and Machado. M. A. 2013. Survey of Xylella fastidiosa and citrus variegated chlorosis in São Paulo State, Brazil. J. Plant Pathol. Online publication. doi:10.4454/JPP.V95I3.005

12. Coletta-Filho, H. D., and Machado, M. A. 2002. Evaluation of the genetic structure of Xylella fastidiosa populations from different Citrus sinensis varieties. Appl. Environ. Microbiol. 68:3731-3736.

13. Coletta-Filho, H. D., and Machado, M. A. 2003. Geographical genetic structure of Xylella fastidiosa from citrus in São Paulo State, Brazil. Phytopathology 93:28-34.

14. Coletta-Filho, H. D., Takita, M. A., Souza, A. A., Aguilar-Vildoso, C. I., and Machado, M. A. 2001. Differentiation of strains of Xylella fastidiosa by a variable number of tandem repeat analysis. Appl. Environ. Microbiol. 67:4091-4095.

15. Cooper, T. F., Paixão, T., Heinemann, J. A. 2010. Within-host competition selects for plasmid-encoded toxin-antitoxin systems. Proc. Biol. Sci. 277:3149-3155.

16. Corander, J., Waldmann, P., and Sillanpaa, M. 2003. Bayesian analysis of genetic differentiation between populations. Genetics 163:367-374.

17. De Souza, A. A., Takita, M. A., do Amaral, A. M., Coletta-Filho, H. D., and Machado, M. A. 2009. Citrus responses to Xylella fastidiosa infection, the causal agent of citrus variegated chlorosis. Pages 73-80 in: Citrus III. Tree and Forestry Science and Biotechnology 3, Special Issue 2. P. Tennant and N. Benkeblia, eds. Global Science Books. Ikenobe, Japan.

18. Ellenger, H. 2000. Microsatellite mutations in the germline: Implications for evolutionary inference. Trends Genet. 16:551-558.

19. Excoffier, L., Laval, G., and Schneider, S. 2005. Arlequin (version 3.11): an integrated software package for population genetics data analysis. Evol. Bioinf. Online 1:47-50.

20. Gerlach, G., Jueterbock, A., Kraemer, P., Deppermann, J., and Harmand, P. 2010. Calculations of population differentiation based on $\mathrm{G}_{\mathrm{ST}}$ and $\mathrm{D}$ : forget $\mathrm{G}_{\mathrm{ST}}$ but not all of statistics! Mol. Ecol. 19:3845-3852.

21. Goudet, J. 1995. FSTAT (version 1.2): A computer program to calculated F-statistics. J. Hered. 86:485-486.

22. Grünwald, N. J., and Goss, E. M. 2011. Evolutionary and population genetics of exotic and re-emerging pathogens: traditional and novel tools and approaches. Annu. Rev. Phytopathol. 49:249-267.

23. Harris, S. R., Feil, E. J., Holden, M. T., Quail, M. A., Nickerson. E. K., Chantratita, N., Gardete, S., Tavares, A., Day, N., Lindsay, J. A., Edgeworth, J. D., de Lencastre, H., Parkhill, J., Peacock, S. J., and Bentley, S. D. 2010. Evolution of MRSA during hospital transmission and intercontinental spread. Science 327:469-474.

24. He, F., and Hu, X. S. 2005. Hubbell's fundamental biodiversity parameter and the Simpson diversity index. Ecol. Lett. 8:386-390.

25. He, M., Sebaihia, M., Lawley, T. D., Stabler, R. A., Dawson, L. F., Martin, M. J., Holt, K. E., Seth-Smith, H. M., Quail, M. A., Rance, R., Brooks, K., Churcher, C., Harris, D., Bentley, S. D., Burrows, C., Clark, L., Corton, C., Murray, V., Rose, G., Thurston, S., van Tonder, A., Walker, D., Wren, B. W., Dougan, G., and Parkhill, J. 2010. Evolutionary dynamics of Clostridium difficile over short and long time scales. Proc. Natl. Acad. Sci. USA 107:7527-7532.

26. Jost, L. 2008. $\mathrm{G}_{\mathrm{ST}}$ and its relatives do not measure differentiation. Mol. Ecol. 17:4015-4026.

27. Laranjeira, F. F., Bergamin, A., and Amorim, L. 1998. Dynamics and structure of citrus variegated chlorosis (CVC) foci. Fitopatol. Bras. 23:3641.

28. Leach, J. E., Vera Cruz, C. M., Bai, J., and Leung, H. 2001. Pathogen fitness penalty as a predictor of durability of disease resistance genes. Annu. Rev. Phytopathol. 39:187-224.

29. Lee, M. W., Rogers, E. E., and Stenger, D. C. 2012. Xylella fastidiosa plasmid-encoded PemK toxin is an endoribonuclease. Phytopathology 102:32-40.

30. Lee, M. W., Stenger, D. C., and Rogers, E. E. 2010. Functional characterization of replication and stability factors of an incP-1 plasmid from Xylella fastidiosa. Appl. Environ. Microbiol. 76:7734-7740.

31. Lin, H., Civerolo, E. L., Hu, R., Barros, S., Francis, M., and Walker, M. A. 2005. Multilocus simple sequence repeat markers for differentiating strains and evaluating genetic diversity of Xylella fastidiosa. Appl. Environ. Microbiol. 71:4888-4892.

32. Lin, W.-H., and Kussell, E. 2012. Evolutionary pressures on simple sequence repeats in prokaryotic coding regions. Nucleic Acids Res. 40:2399-2413

33. McDonald, B. A., and Linde, C. 2002. Pathogen population genetics, evolutionary potential, and durable resistance. Annu. Rev. Phytopathol. 40:349-379.

34. Meirmans, P., and van Tienderen, P. 2004. GENOTYPE and GENODIVE: two programs for the analysis of genetic diversity of asexual organisms. Mol. Ecol. Notes 4:792-794.

35. Nei, M. 1978. Estimation of average heterozygosity and genetic distance from a small number of individuals. Genetics 89:583-590.

36. Purcell A. H.1981. Vector preference and inoculation efficiency as components of resistance to Pierce's disease in European grape cultivars. Phytopathology 71:429-435.

37. Real, L. A., Henderson, J. C., Biek, R., Snaman, J., Lambert-Jack, T., Childs, J. E., Stahl, E., Waller, L., Tinline, R., and Nadin-Davis, S. 2005. Unifying the spatial population dynamics and molecular evolution of epidemic rabies virus. Proc. Natl. Acad. Sci. USA 102:12107-12111.

38. Restrepo, S., Velez, C. M., Duque, M. C., and Verdier, V. 2004. Genetic structure and population dynamics of Xanthomonas axonopodis pv. manihotis in Colombia from 1995 to 1999. Appl. Environ. Microbiol. 70:255-261.

39. Rousset, F. 1997. Genetic differentiation and estimation of gene flow from F-Statistics under isolation by distance. Genetics 145:1219-1228.

40. Schaad, N. W., Lacy, P. E. G., Fatmi, M., and Chang, C. J. 2004. Xylella fastidiosa subspecies: $X$. fastidiosa subsp. piercei, subsp. nov., $X$. fastidiosa subsp. multiplex subsp. nov., X. fastidiosa subsp. pauca subsp. nov. Syst. Appl. Microbiol. 27:290-300.

41. Scortichini, M. 2005. The population structure of some plant pathogenic bacteria: an ecological and adaptive perspective. J. Plant Pathol. 87:5-12.

42. Sharma, A. M., Wang, J., Duffy, S., Zhang, S., Wong, M. K., Rashed, A., Cooper, M. L., Daane, K. M., and Almeida, R. P. P. 2011. Occurrence of grapevine leafroll-associated virus complex in Napa Valley. PLoS One 6:e26227.

43. Slatkin, M. 1995. A measure of population subdivision based on microsatellite allele frequencies. Genetics 139:457-462.

44. Treangen, T. J., Abraham, A. L., Touchon, M., and Rocha, E. P. C. 2009. Genesis, effects and fates of repeats in prokaryotic genomes. FEMS Microbiol. Rev. 33:539-571.

45. van Belkum, A., Scherer, S., van Alphen, L., and Verbrugh, H. 1998. Short-sequence DNA repeats in prokaryotic genomes. Microbiol. Mol. Biol. Rev. 62:275-293.

46. Waples, R., and Gaggiotti, O. 2006. What is population? An empirical evaluation of some genetic methods for identifying the number of gene pools and their degree of connectivity. Mol. Ecol. 15:1419-1439.

47. Young, B. C., Golubchik, T., Batty, E. M., Fung, R., Larner-Svensson, H., Votintseva, A. A., Miller, R. R., Godwin, H., Knox, K., Everitt, R. G., Iqbal, Z., Rimmer, A. J., Cule, M., Ip, C. L., Didelot, X., Harding, R. M., Donnelly, P., Peto, T. E., Crook, D. W., Bowden, R., and Wilson, D. J. 2012. Evolutionary dynamics of Staphylococcus aureus during progression from carriage to disease. Proc. Natl. Acad. Sci. USA 109:45504555.

48. Zhan, J., Pettway, R. E., and McDonald, B. A. 2003. The global genetic structure of the wheat pathogen Mycosphaerella graminicola is characterized by high nuclear diversity, low mitochondrial diversity, regular recombination, and gene flow. Fungal Genet. Biol. 38:286-297. 